\title{
MEDICARE ADVANTAGE IN 2007: WHAT CONGRESS INTENDED?
}

\author{
by \\ Marsha Gold, Sc.D. \\ Senior Fellow \\ Mathematica Policy Research
}

June 22, 2007

For presentation at Niflp Fession Panel on "IJecligare Advantage in 2007: Wirat are the Chrojees?" 


\section{Overview of Findings - I}

- Changes in Medicare Advantage in the MMA reversed the prior erosion in private plan availability and enrollment under Medicare+Choice.

Shift began before 2006 (Part D benefit and changes) but intensified thereafter 


\section{Overview of Findings - II}

- PFFS accounts disproportionately for growth in MA availability and enrollment across the country.

- As a replacement supplement, PFFS provides attractive premiums with the promise of open access. But financial and access risk in PFFS typically is higher than in Medigap and perhaps higher than beneficjaries expect. 


\section{Key Features of Selected MA Contracts by Type}

\begin{tabular}{|c|c|c|c|c|}
\hline & HMO & LPPO & RPPO & PFFS \\
\hline First Authority & TERFA (1985) & BBA (1999) & MMA (2006) & BBA (1999) \\
\hline Service Area & $1+$ Counties & 1+ Counties & $\begin{array}{l}27 \text { Regions } \\
1+\text { States }\end{array}$ & 1+ Counties \\
\hline Benefits & Medicare Actuarial & Medicare Actuarial & $\begin{array}{l}\text { Actuarial } \\
\text { +OOP Limit + } \\
\text { Integrated A/B Cost } \\
\text { Sharing }\end{array}$ & Medicare Actuarial \\
\hline Benchmark & County FFS & County FFS & $\begin{array}{l}\text { Blend County FFS + } \\
\text { Bid Over Region }\end{array}$ & County FFS \\
\hline Payment & $\begin{array}{l}\text { Lower of Bid or } 75 \% \\
\text { Benchmark }\end{array}$ & $\begin{array}{l}\text { Lower of Bid or } 75 \% \\
\text { Benchmark }\end{array}$ & $\begin{array}{l}\text { Lower of Bid or } 75 \% \\
\text { Benchmark }\end{array}$ & $\begin{array}{l}\text { Lower of Bid or } \\
75 \% \text { Benchmark }\end{array}$ \\
\hline CMS Risk Sharing & No & No & Yes & No \\
\hline Required Part D? & 1+ Plan & 1+ Plan & All Plans & No \\
\hline Required Network & Yes & Yes & Yes & No \\
\hline $\begin{array}{l}\text { Required Baseline } \\
\text { Health Assessment } \\
\text { and Care } \\
\text { Coordination }\end{array}$ & Yes & Yes & Yes & No \\
\hline Required HEDIS & Yes & Yes & Yes & No \\
\hline Required QI/UR & Yes & Yes & Yes & No \\
\hline
\end{tabular}




\section{Context of Growing Industry Interest in MA}

1. Entire Medicare program in transition with Part D

2. MMA introduced favorable rates

3. Aging of products makes senior products demographically all activities

Source: MPR firm interviews for ASPE 2006 (Gold and Peterson 2006) 


\section{Firm Strategies to Balance Resource Demands to Expand MA and PDP}

- Built on Base

- Targeted "low hanging fruit"

- Favored strategies consistent with market strength

, Expand with consideration of full book of business

- Tailor level of business risk

- Respond to market strategjes 


\section{Firm MA Strategies - I}

2006

- Limited by resources spent developing PDPs

Some motivated by threats to book of business vs. opportunity

- Firm decjsjon on products strongly influenced by county IJA payment rates and provider network decisjons 


\section{Firm MA Strategies - II}

2007 (Moratorium on new local PPOs)

- Refining strategies in response to market competition ("tweak benefits, premiums")

, Respond to growth PFFS

Additional time to develop SNPS, new work product

Source: MPPR firm interviews for ASPE 2006 (Gold and Peterson 2006) 


\section{Firm Perceptions on RPPO vs. PFFS - I}

RPPO

- Resources demands high to create provider networks across large geographic areas

, Challenging to negotiate rates with providers

- Concerned about market viability of product with uniform benefits over broad areas competing with local plans 


\section{Firm Perceptions on RPPO vs. PFFS - II}

PFFS

- Ability to sidestep provider contracts by using Medicare rates

- Less need for local presence so administrative costs shared nationally

- Local rates so can vary offerings/marketing by areas

- Familiar to nationwide brokers and agents 
Number of Coordinated and PFFS

\section{Contracts Available to Beneficiaries By County Type, 2007}

\begin{tabular}{lcccccc}
\hline & \multicolumn{2}{c}{ All Beneficiaries } & \multicolumn{2}{c}{ Urban Beneficiaries } & \multicolumn{2}{c}{ Rural Beneficiaries } \\
\hline $\begin{array}{l}\text { Percentage of } \\
\text { Beneficiaries with: }\end{array}$ & CCPa & PFFS & CCPa & PFFS & CCPa & PFFS \\
\hline None & $1.5 \%$ & $0.3 \%$ & $0.7 \%$ & $0.0 \%$ & $4.3 \%$ & $0.0 \%$ \\
\hline 1 & 12.5 & 2.7 & 5.8 & 3.4 & 36.3 & 0.4 \\
\hline 2 & 16.0 & 6.1 & 11.1 & 7.5 & 33.9 & 1.6 \\
\hline $3-5$ & 33.9 & 35.9 & 39.3 & 35.2 & 16.7 & 40.0 \\
\hline 6 or More & 33.7 & 52.4 & 43.2 & 53.4 & 2.3 & 51.4 \\
\hline
\end{tabular}

Source: MPR analysis of a file created from the 2007 Personal Plan Finder.

Note: Contracts reflect unique organizational sponsors. Each contract may include several plans (that is, different benefit packages). Exclude employer-only " $800 "$ plans.

ancludes R-PPOs which are available to most beneficiaries. 


\section{Distribution of MA Enrollment, Total and HMO 1999-2007 (millions)}

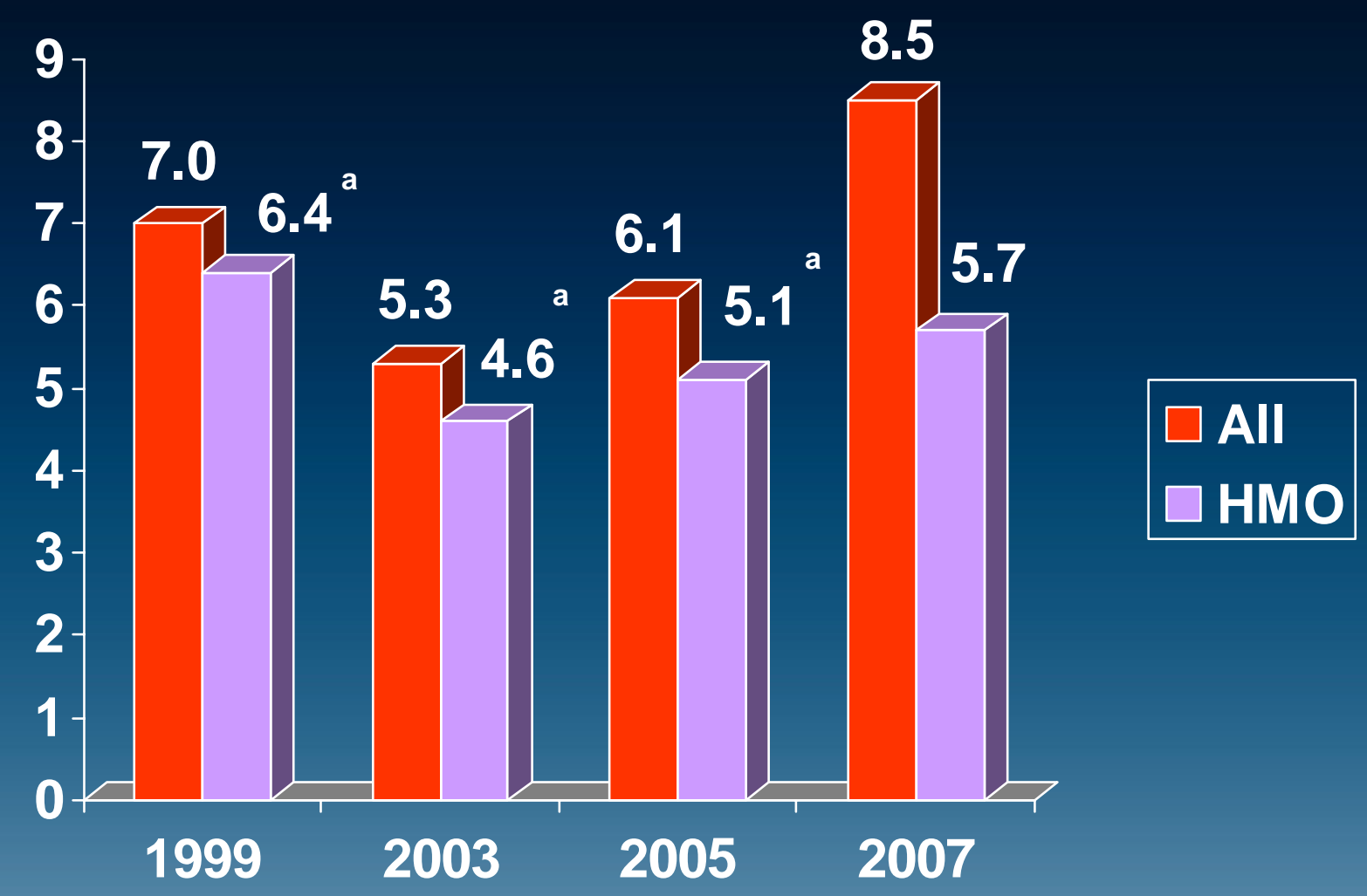

Source: CMS Monthly Health Plan Summary Report. December 1999-2003; April for 2007.

${ }^{a}$ May include a few enrollees in PPOs/POS but excludes PPO demonstration. 


\section{Distribution of MA Enrollment, May 2007}

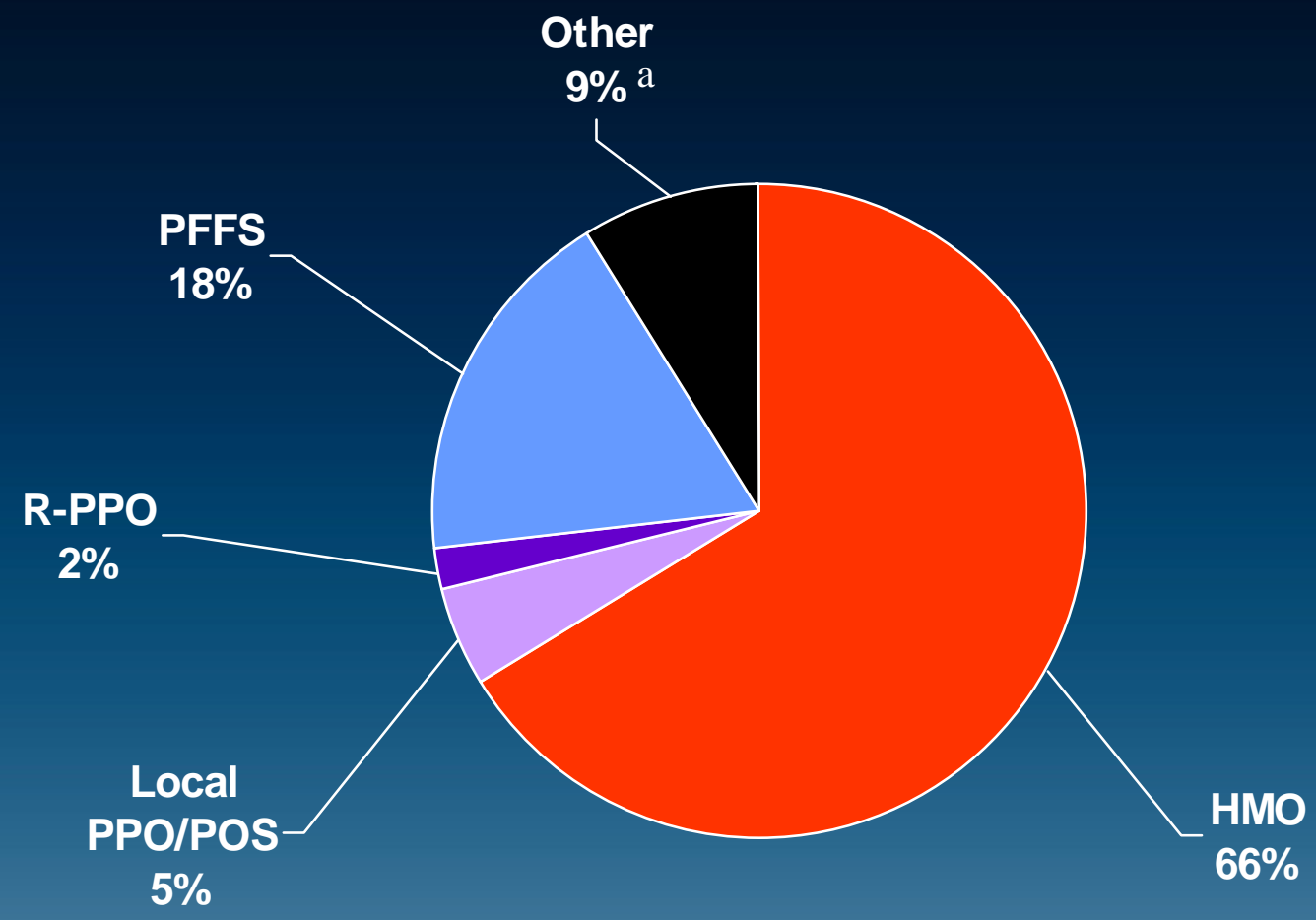

Total Enrollment $=8.6$ million

Source: CMS Monthly Health Plan Summary Report.

ancludes cost, demonstration and other plans. Enrollment in MSAs was 2,261. 


\section{Major PFFS Firms in MA, 2007}

\section{Enrollment}

Percent of Beneficiaries with Available Plan

\begin{tabular}{|c|c|c|c|}
\hline All Firms & $97 \%$ & 819,098 & $1,329,296$ \\
\hline \multicolumn{4}{|l|}{ Firms with 5,000 + Enrollees } \\
\hline Humana & $83 \%$ & 468,064 & 572,058 \\
\hline UnitedHealthcare/Pacificare & $40 \%$ & 176,180 & 102,064 \\
\hline Wellpoint (Unicare, Anthem) & $68 \%$ & 75,462 & 98,575 \\
\hline Sterling & High & 48,222 & 67,902 \\
\hline BCBS of Michigan & Low & 28,677 & 149,095 \\
\hline Heritage Health Systems ${ }^{a}$ & High & 15,955 & 96,087 \\
\hline Coventryb & High & 0 & 75,664 \\
\hline Universal Health Carec & Medium & 0 & 72,793 \\
\hline Aetna & $4 \%$ & 0 & 37,064 \\
\hline Wellcare & Medium & 0 & 17,721 \\
\hline Harvard Pilgrim & Low & 0 & 16,133 \\
\hline
\end{tabular}

Source: MPR analysis of files created from CMS data on enrollment by contract and county.

${ }^{a}$ Includes American Progressive Life and Pyramid Life Insurance Company.

bIncludes First Health Life, Coventry, and Cambridge Life.

cAny, Any, Any Plan. 


\section{Distribution of March 2007 Enrollment by Payment Level}

\begin{tabular}{llcccc}
\hline County Benchmark & All & HMO & Local PPO & R-PPO & PFFS \\
\hline Rural Floor (\$662) & $8.6 \%$ & $2.8 \%$ & $7.2 \%$ & $11.7 \%$ & $29.4 \%$ \\
\hline$\$ 663-\$ 731$ & 2.3 & 0.9 & 2.4 & 6.5 & 6.0 \\
\hline Urban Floor (\$732) & 29.9 & 26.4 & 36.4 & 22.8 & 42.9 \\
\hline$\$ 733-\$ 795$ & 17.1 & 19.8 & 13.2 & 22.8 & 9.7 \\
\hline$\$ 796-\$ 895$ & 21.6 & 25.0 & 15.9 & 25.8 & 6.9 \\
\hline$\$ 896$ and more & 20.5 & 25.2 & 24.9 & 10.4 & 5.1 \\
\hline Total Enrollment (1,000s) & $(7,606)$ & $(5,204)$ & $(389)$ & $(113)$ & $(1,329)$ \\
\hline
\end{tabular}

Source: MPR analysis of files created from CMS data on enrollment by contract and county.

Note: Excludes enrolls in Puerto Rico and the territories and any SNP only contracts. 


\section{PFFS "Selling Points"}

- "One Stop" Shopping (if Rx)

- Premiums substantially less than Medigap

- Reconfigured Medicare A/B cost sharing (but poorly understood)

- Potential access to "any willing provider"

- Some addjitional benefits- largely preventive 


\section{Benefits in HMO Versus PFFS MA-PD Plans, 2006}

\begin{tabular}{lccccc}
\hline & \multicolumn{2}{c}{ HMOs } & & \multicolumn{2}{c}{ PFFS } \\
\cline { 2 - 3 } \cline { 6 - 7 } & All & $\begin{array}{c}\text { Lowest } \\
\text { Premium }\end{array}$ & & Alla & $\begin{array}{c}\text { Lowest } \\
\text { Premium }\end{array}$ \\
\hline Average MA Total Premium Per Month & $\$ 39$ & $\$ 22$ & & $\$ 48$ & $\$ 44$ \\
\hline Percent with Zero Premiums & $44 \%$ & $64 \%$ & & $19 \%$ & $24 \%$ \\
\hline Percent Rx Benefits in Gap & $31 \%$ & $26 \%$ & & $0 \%$ & $0 \%$ \\
\hline PCP copay over $\$ 25$ & $1 \%$ & $1 \%$ & & $0 \%$ & $0 \%$ \\
\hline Spec copay over $\$ 25$ & $22 \%$ & $29 \%$ & & $57 \%$ & $73 \%$ \\
\hline Median Three Day IP Stay & -- & $\$ 300$ & & -- & $\$ 540$ \\
\hline Median Three IP Stays & -- & $\$ 1,300$ & & -- & $\$ 2,340$ \\
\hline
\end{tabular}

Source: MPR analysis of a file created from CMS's November 2005 Personal Plan Finder.

aFigures only for MA-PDs. 70 percent of PFFS plans had drug coverage; premiums for MA only plans are $\$ 38$ per month on average, with 20 percent having no premium. Among all PFFS plans, 38 percent have a specialist copay of $\$ 25$ or more.

${ }^{\text {b}}$ Two 2 six day stays and one three day stays. 
Estimated Out-of-Pocket Costs Per

\section{Enrollee for Hospital and Physician Services in MA-PD Plans by Type, 2006}

\begin{tabular}{|c|c|c|c|c|c|}
\hline $\begin{array}{l}\text { Estimated Annual Out-of-Pocket } \\
\text { Costs Per Enrollee for Hospital } \\
\text { and Physician Services, by } \\
\text { Health Statues }\end{array}$ & All & HMO & Local PPO & PFFS & $\begin{array}{c}\text { Regional } \\
\text { PPO }\end{array}$ \\
\hline \multicolumn{6}{|l|}{ All MA-PD (Except SNPs) } \\
\hline All & $\$ 268$ & $\$ 239$ & $\$ 303$ & $\$ 337$ & $\$ 432$ \\
\hline Healthy & $\$ 831$ & $\$ 72$ & $\$ 104$ & $\$ 81$ & $\$ 180$ \\
\hline Episodic Needs & $\$ 686$ & $\$ 621$ & $\$ 749$ & $\$ 911$ & $\$ 983$ \\
\hline Chronic Needs & $\$ 1,656$ & $\$ 1,487$ & $\$ 1,819$ & $\$ 2,254$ & $\$ 2,382$ \\
\hline Number of Contract Segments & 1,349 & 909 & 269 & 126 & 47 \\
\hline
\end{tabular}

Source: MPR analysis of CMS's November 2005 Personal Plan Finder using HealthMetrix cost sharing methodology . SNP plans are excluded. The method is based on assumptions of use of hospital and physician services by beneficiaries in three categories of health status. Out-of-pocket costs are based on application of actual plan benefits to these assumptions. The "all" category weights the three groups by the data from the Medicare Current Beneficiary Survey on the share of beneficiaries with at least good, with fair, and with poor health status. 


\section{Question 1}

- If the major accomplishment post-MMA is that over half of all Medicare beneficiaries +0 now chose among plans from $6+$ PFFS sponsors-and PFFS enrollment growth accounts for a large share of the growth in MA-is this a success? 


\section{Question 2}

- Beneficiaries are concerned about financial protection but many struggle/cannot afford Medigap. Minorities are disproportionately affected though economic concerns touch most beneficiaries. What is the best solution to this issue? 


\section{For Additional Information}

- Marsha Gold. "Medicare Advantage in 2006-2007: What Congress Intended? Health Affairs Web Exclusive May 15, 2007. See www.healthaffairs.org

- Marsha Gold. "Private Plan in Medicare: A 2007 Update." Washington, DC: Kaiser Family Foundation, March 2007. See www.kff.org for this and earlier papers.

, Marsha Gold and Stephanie Peterson. "Analysis of the Characteristics of Medicare Advantage Particjpation." Report prepared for the Assistant Secretary for Planning and Evaluation. US Department of Health and Human Services, 2006. See wyy mathematica-mpr.com for this and other papers on $M J+C / M M A$. 


\section{BONUS SLIDES}

MATHEMATICA

Policy Research, Inc. 


\section{Where Do SNPs Fit?}

- HMOs, PPOs, PFFS = Contract Types

- Available historically any beneficiary

- May offer 1+ plans (different benefits and premiums)

, SNPs = are distinct Plans offered under diverse contact types. Enrollment is available only (or disproportionately) to subgroups of beneficiaries (duals, institutionalized, chronic illness)

- SNPS CANNOT be PFFS

- Mjost SNIPS are HINOS or prior demonstrations. Some are PPOS or RHPPOS. 


\section{Percentage of Beneficiaries in Urban and Rural Areas with Available MA Plan, 2005-2007}

\begin{tabular}{lccccccc}
\hline & \multicolumn{3}{c}{ Urban } & & \multicolumn{3}{c}{ Rural } \\
\cline { 2 - 5 } \cline { 5 - 8 } Percent with & 2005 & 2006 & 2007 & & 2005 & 2006 & 2007 \\
\hline Any MA Plan & 96 & 100 & 100 & & 78 & 93 & 94 \\
\hline Any Local HMO/PPO/PSO & 78 & 89 & 91 & & 38 & 42 \\
\hline Any PFFS & 38 & 76 & 100 & & 51 & 94 & 96 \\
\hline Any R-PPO & 0 & 88 & 88 & & 0 & 84 & 84 \\
\hline Any MSA & 0 & 0 & 73 & 0 & 0
\end{tabular}

Source: MPR Analysis of files created from CMS data on Geographic Service Area Report (2005) and Medicare Personal Plan Finder (2006, 2007). 
Percent of Beneficiaries with Available MA Plan by Selected Firm and
Contract Type, 2007

\begin{tabular}{lcccccc}
\hline & $\begin{array}{c}\text { Any } \\
\text { Contract }\end{array}$ & $\begin{array}{c}\text { Local } \\
\text { HMO }\end{array}$ & $\begin{array}{c}\text { Local } \\
\text { PPO }\end{array}$ & $\begin{array}{c}\text { Regional } \\
\text { PPO }\end{array}$ & PFFS & MSA \\
\hline Humana & $83 \%$ & $11 \%$ & $13 \%$ & $59 \%$ & $83 \%$ & 0 \\
\hline United Healthcare & $73 \%$ & $37 \%$ & $10 \%$ & $14 \%$ & $40 \%$ & 0 \\
\hline Wellpoint/Unicareb & $68 \%$ & $9 \%$ & $5 \%$ & $8 \%$ & $28 \%$ & $60 \%$ \\
\hline Non-Wellpoint/BCBS & $54 \%$ & $29 \%$ & $23 \%$ & $14 \%$ & $8 \%$ & $10 \%$ \\
\hline Aetna & $28 \%$ & $23 \%$ & $11 \%$ & $5 \%$ & $4 \%$ & 0 \\
\hline Kaiser-Permanente & $15 \%$ & $12 \%$ & 0 & 0 & 0 & 0 \\
\hline
\end{tabular}

\section{aAlso includes cost contracts.}

bUnder UniCare (a non-Blue branded entity), Wellpoint also offers MSAs to 60 percent of beneficiaries, PFFS plans to 24 percent, and HMOs to one percent. UniCare products by Wellpoint are included in the "other" category because they are not Blue branded. In total, Wellpoint products (including UniCare) were available to at least 68 percent of all Medicare beneficiaries. 


\section{PFFS Enrollment Growth, Selected Dates, 2001-2007}

December 2000

December 2001

December 2002

December 2003

December 2004

December 2005

December 2006
1,178

19,835

22,728

25,890

51,214

208,990

864,100
February 2007

March 2007

April 2007

May 2007

$1,338,026^{a}$

$1,379,277^{a}$

$1,494,955^{a}$

$1,558,371^{a}$

Source: CMS Monthly Report, various years.

ancludes cost, demonstration and other plans. Enrollment in MSAs was around 2,200. 


\section{Growth in Enrollment By County Payment Rate, All MA, and PFFS, 2005-2007 (in 1,000s)}

\begin{tabular}{|c|c|c|c|c|c|c|c|c|}
\hline \multirow[b]{2}{*}{$\begin{array}{l}\text { County } \\
\text { Benchmark }\end{array}$} & \multicolumn{4}{|c|}{ All MA } & \multicolumn{4}{|c|}{ PFFS } \\
\hline & $\begin{array}{l}\text { Dec. } \\
2005\end{array}$ & $\begin{array}{l}\text { Nov. } \\
2006\end{array}$ & $\begin{array}{c}\text { March } \\
2007\end{array}$ & Change & $\begin{array}{l}\text { Dec. } \\
2005\end{array}$ & $\begin{array}{l}\text { Nov. } \\
2006\end{array}$ & $\begin{array}{c}\text { March } \\
2007\end{array}$ & Change \\
\hline All Counties & 5,466 & 6,962 & 7,606 & $+2,140$ & 199 & 819 & 1,329 & $+1,130$ \\
\hline Rural Floor & 529 & 533 & 652 & +123 & 77 & 294 & 390 & +313 \\
\hline Between Floors & 61 & 127 & 178 & +117 & 7 & 36 & 80 & +73 \\
\hline Urban Floor & 1,545 & 2,067 & 2,271 & +726 & 96 & 397 & 570 & +474 \\
\hline Above Floors & 3,331 & 4,235 & 4,506 & $+1,175$ & 18 & 92 & 289 & +271 \\
\hline
\end{tabular}

Source: MPR analysis of files created from CMS data on enrollment by contract and county.

Note: Excludes enrolls in Puerto Rico and the territories and any SNP only contracts. 


\section{Cost Sharing/Additional Benefits in Medicare and Medigap, 2006}

\begin{tabular}{lcc}
\hline & Medicare Only & Medigap C/F \\
\hline Hospital Inpatient & & None \\
\hline Deductible & $\$ 952$ & None \\
\hline Coinsurance & $\begin{array}{c}\$ 230 / \text { day } \\
(61-90) \\
\$ 476 / \text { day } \\
(91-150)\end{array}$ & None \\
\hline Limits & $\begin{array}{c}150 \text { days/year } \\
+60 \text { Lifetime } \\
\text { Days }\end{array}$ & \\
\hline Physician & $\begin{array}{c}\$ 124 \\
\text { Deductible }\end{array}$ & F = \$124 \\
\hline Coinsurance & $20 \%$ & None (F covers excess) \\
\hline Out-of-Pocket Limit & None & None (but little cost sharing) \\
\hline
\end{tabular}

